\title{
Study on EPS thermal insulation mortar prepared by magnesium oxychloride cement
}

\author{
Shiming Huang ${ }^{1}$, Wen Zhu ${ }^{1, *}$, Yanli Zhang ${ }^{1}$, Dehui Lu², and Ruying Zhao ${ }^{1}$ \\ ${ }^{1}$ Guangzhou Testing Centre of Construction Quality \& Safety Co., Ltd., 833 Baiyun Avenue North, Guangzhou, 510440, China \\ ${ }^{2}$ Guangzhou Construction Engineering Co., Ltd. 4 Guangwei Road, Guangzhou, 510030, China
}

\begin{abstract}
In this paper, a composite thermal insulation mortar was prepared with magnesium oxychloride cement and polystyrene (EPS) particles. The influence of EPS particles content on the mechanical strength, density and thermal conductivity of composite thermal insulation mortar was studied. Also, the effect of fly ash on the density and thermal conductivity of the mortar was researched. It was shown that: (1) Generally, EPS particles could reduce the compressive strength, flexural strength, density and thermal conductivity of the mortar. The 28 days compressive strength and 28 days flexural strength decreased by $93.3 \%$ and $81.3 \%$ respectively, with the content of EPS particles from $0 \%$ to $0.486 \%$. Also the density of the mortar was reduced from $2043 \mathrm{~g} / \mathrm{dm}^{3}$ to $805 \mathrm{~g} / \mathrm{dm}^{3}$, and the thermal conductivity was fell from $0.4093 \mathrm{~W} /(\mathrm{m} \cdot \mathrm{K})$ to $0.2191 \mathrm{~W} /(\mathrm{m} \cdot \mathrm{K})$. (2) Small amounts (less than $5.487 \%$ ) of fly ash could increase the density and thermal conductivity. However, when the content of fly ash was more than $5.487 \%$, the density and thermal conductivity of thermal insulation mortar were significantly reduced.
\end{abstract}

\section{Introduction}

Polystyrene (EPS) particles are manufactured from waste polystyrene plastics. Due to the characteristics of light weight, low thermal conductivity, low water absorption, good thermal insulation effect, and crack resistance, EPS particles are usually used to replace traditional inorganic aggregates to make light-weight thermal insulation materials. However, EPS materials is flammable in fire with the droplet phenomenon, which will intensify the combustion of EPS. So there is a potential security risks. Therefore, improving the flame retardant performance of EPS insulation materials has important research significance [1-3]. The studies show that [4-7], EPS composite thermal insulation mortar prepared with EPS particles as aggregate has a good thermal insulation and flame retardancy.

Magnesium oxychloride cement (Sorell's cement) is a magnesium cement stone obtained by mixing magnesium chloride aqueous solution and activated magnesium oxide $(\mathrm{MgO})$ powder. Also, the magnesium cement stone is a magnesium cementitious material composed of $\mathrm{MgO}-\mathrm{MgCl}_{2}-\mathrm{H}_{2} \mathrm{O}$ material system, which has good bonding performance, high mechanical strength, high-low temperature resistance, good air stability and weather resistance, as well as light weight and low corrosion resistance etc. So it can be used in the field of flame retardant [8].
In this paper, the mass ratio $\mathrm{m}(\mathrm{MgO}) / \mathrm{m}$ (magnesium chloride aqueous solution $) / \mathrm{m}\left(\mathrm{H}_{2} \mathrm{O}\right)$ was $7.41 / 5.09 / 1$ as the matrix of magnesium oxychloride cement, and EPS particles were mixed to prepare composite thermal insulation mortar. The influence of EPS content on mechanical strength, density and thermal conductivity of thermal insulation mortar were studied. Also, the effect of fly ash on the density and thermal conductivity of thermal insulation mortar with the EPS particles content of $0.486 \%$ were studied.

\section{Materials and Methods}

\subsection{Materials}

Magnesium oxide $(\mathrm{MgO})$ is from Beijing Li Fu Sheng Chemical Industry Co., Ltd, of which the chemical composition is shown in table 1. Magnesium chloride $\left(\mathrm{MgCl}_{2}\right)$ is from Henan Xin Hong Tai Biological Technology Co., Ltd, and the content of $\mathrm{MgCl}_{2} \cdot \mathrm{H}_{2} \mathrm{O}$ is $99.1 \%$. Also, magnesium chloride aqueous solution for experiment was made of $\mathrm{MgCl}_{2} \cdot \mathrm{H}_{2} \mathrm{O}$ and water with molar ratio of $\mathrm{MgCl}_{2} \cdot \mathrm{H}_{2} \mathrm{O}$ /water was maintained at $1 / 10$. EPS particles as aggregate are produceed by Beijing Shun Gang Zhu Bang Ecotechnology Co., Ltd. Fly ash is provied by Shaoguan Qu Jiang Wu Shi Gang Co., Ltd, of which 's performances is shown in Table 2.

Table 1. Chemical composition of magnesium oxide.

\begin{tabular}{llllllllll}
\hline Composition & $\mathrm{MgO}$ & $\mathrm{SiO}_{2}$ & $\mathrm{CaO}$ & $\mathrm{Al}_{2} \mathrm{O}_{3}$ & $\mathrm{Fe}_{2} \mathrm{O}_{3}$ & $\mathrm{SO}_{3}$ & $\mathrm{P}_{2} \mathrm{O}_{5}$ & $\mathrm{MnO}$ & $\mathrm{K}_{2} \mathrm{O}$ \\
\hline Proportion (\%) & 85.7 & 11.7 & 1.49 & 0.41 & 0.39 & 0.13 & 0.06 & 0.02 & 0.02 \\
\hline
\end{tabular}

\footnotetext{
* Corresponding author: wenzi311@163.com
} 
Table 2. Chemical composition of fly ash.

\begin{tabular}{lllllllllll}
\hline Composition & $\mathrm{SiO}_{2}$ & $\mathrm{Al}_{2} \mathrm{O}_{3}$ & $\mathrm{CaO}$ & $\mathrm{Fe}_{2} \mathrm{O}_{3}$ & $\mathrm{TiO}_{2}$ & $\mathrm{~K}_{2} \mathrm{O}$ & $\mathrm{SO}_{3}$ & $\mathrm{MgO}$ & $\mathrm{Na}_{2} \mathrm{O}$ & Others \\
\hline Proportion (\%) & 50.15 & 39.2 & 2.54 & 1.71 & 2.18 & 2.45 & 0.60 & 0.42 & 0.34 & 0.41 \\
\hline
\end{tabular}

decreases more than flexural strength. The 3 days

\subsection{Experimental methods}

The effect of EPS on mechanical properties, density and thermal conductivity of composite insulation mortar was studied in this experiment. Mechanical properties experiments were conducted according to Chinese standard "Method of testing cements-Determinnation of strength" GB/T 17671-1999, with the sample size of 40 $\mathrm{mm} \times 40 \mathrm{~mm} \times 160 \mathrm{~mm}$. The thermal conductivity was measured by the heat flow method thermal conductivity analyzer (HFM), and the sample was poured with size of $300 \mathrm{~mm} \times 300 \mathrm{~mm} \times 25 \mathrm{~mm}$. And the mix ratios of mortar are shown in table 3 .

Table 3. Test matrix of thermal insulation mortar (w\%).

\begin{tabular}{ccccc}
\hline No. & EPS & $\mathrm{MgO}$ & $\begin{array}{c}\text { Magnesium chloride } \\
\text { aqueous solution }\end{array}$ & $\mathrm{H}_{2} \mathrm{O}$ \\
\hline 1 & 0.000 & 54.870 & 37.723 & 7.407 \\
2 & 0.032 & 54.870 & 37.723 & 7.407 \\
3 & 0.097 & 54.870 & 37.723 & 7.407 \\
4 & 0.162 & 54.870 & 37.723 & 7.407 \\
5 & 0.227 & 54.870 & 37.723 & 7.407 \\
6 & 0.291 & 54.870 & 37.723 & 7.407 \\
7 & 0.357 & 54.870 & 37.723 & 7.407 \\
8 & 0.421 & 54.870 & 37.723 & 7.407 \\
9 & 0.486 & 54.870 & 37.723 & 7.407 \\
\hline
\end{tabular}

In order to improve the water resistance and stability of the composite thermal insulation mortar, in this part, fly ash were used to replace part of the $\mathrm{MgO}$. And the influence of fly ash on density and thermal conductivity of thermal insulation mortar were studied. The compositions are listed in Table 4.

Table 4. Test matrix (different fly ash contents) (w\%).

\begin{tabular}{|c|c|c|c|c|c|}
\hline No. & EPS & Fly ash & $\mathrm{MgO}$ & $\begin{array}{l}\text { Magnesium } \\
\text { chloride } \\
\text { aqueous } \\
\text { solution }\end{array}$ & $\mathrm{H}_{2} \mathrm{O}$ \\
\hline 1 & 0.486 & 0.000 & 54.870 & 37.723 & 7.407 \\
\hline 2 & 0.486 & 2.743 & 52.126 & 37.723 & 7.407 \\
\hline 3 & 0.486 & 5.487 & 49.383 & 37.723 & 7.407 \\
\hline 4 & 0.486 & 8.230 & 46.639 & 37.723 & 7.407 \\
\hline 5 & 0.486 & 10.974 & 43.896 & 37.723 & 7.407 \\
\hline
\end{tabular}

\section{Results and Discussion}

\subsection{The influence of EPS particles on mechanical properties}

It can be seen from figure 1 and figure 2, that with the increase of EPS particles content, compressive strength and flexural strength of thermal insulation mortar both showed a downward trend, and the compressive strength compressive strengths, 7 days compressive strengths and 28 days compressive strengths were 87.2 $\mathrm{MPa}, 100.0$ $\mathrm{MPa}$ and $130.5 \mathrm{MPa}$, respectively, and the flexural strengths of 3 days, 7 days and 28 days were $19.5 \mathrm{MPa}$, $20.6 \mathrm{MPa}$ and $21.3 \mathrm{MPa}$, when the EPS content of $0 \%$. As the content of EPS particles increases, the compressive strength and flexural strength continue to decrease, reached the minimum when the content was $0.486 \%$. The reason could be that the tensile strength and compressive strength of EPS particles are less than those of magnesium oxychloride cement, becuase of its good deformability. So, undering the stress, the hardened magnesium oxychloride cement played the role of bearing the main stress. With the addition of EPS particles, the proportion of magnesium oxychloride cement reduced, that leaded to decline the compressive strength and flexural strength. In addition, EPS particles are organic polymer materials, while magnesium oxychloride cement is an inorganic material, and the surface properties of them are different, which shows the low interface bond strength. When continuous loading, it is easy to produce micro-cracks at the interface. Therefore, the more EPS particles were used, the more micro-cracking were formed at interface, so the lower the mechanical strength [9].

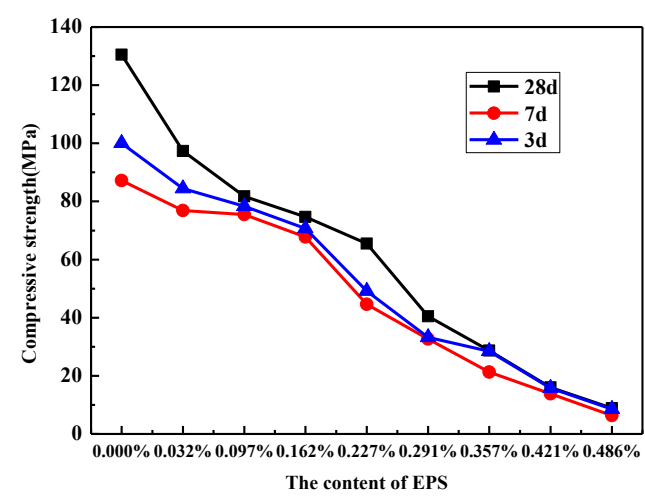

Fig. 1. The relationship between EPS particle content and compressive strength

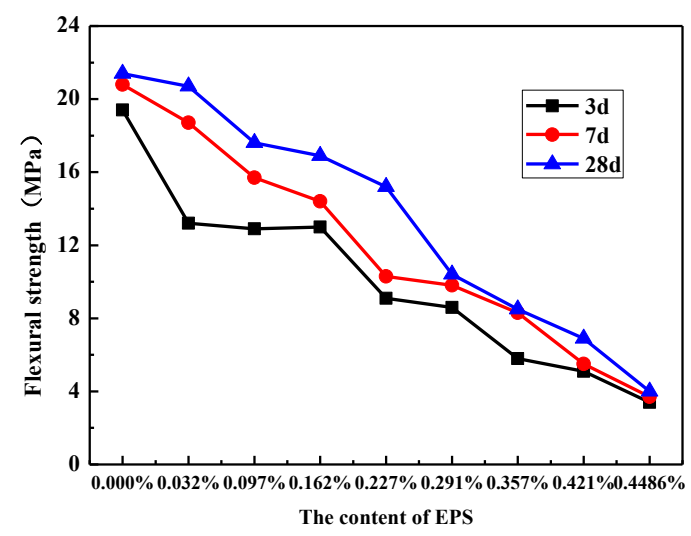

Fig. 2. The relationship between EPS particle content and flexural strength 


\subsection{The influence of EPS particles on thermal conductivity and density}

In this part, the effect of EPS on thermal conductivity and density were studied. As can be seen from figure 3, the density and thermal conductivity of the thermal insulation mortar decreased as the increase of EPS particles. The density of the mortar was reduced from $2043 \mathrm{~g} / \mathrm{dm}^{3}$ to $805 \mathrm{~g} / \mathrm{dm}^{3}$ with the content of EPS particles from $0 \%$ to $0.486 \%$, and the thermal conductivity was fell from $0.4093 \mathrm{~W} /(\mathrm{m} \cdot \mathrm{K})$ to 0.2191 $\mathrm{W} /(\mathrm{m} \cdot \mathrm{K})$. Due to the low density and low thermal conductivity, with the EPS content increase, the density of the thermal insulation mortar decreased, and the thermal conductivity diminished. What's more, EPS particles are organic polymer materials with the hydrophobicity, which is easy to produce closed pores at the interface between EPS particles and cement slurry [10]. Finally, excessive incorporation of EPS could cause the growth of the closed pores formed at the interface, which would make a low density and thermal conductivity of the mortar decreased.

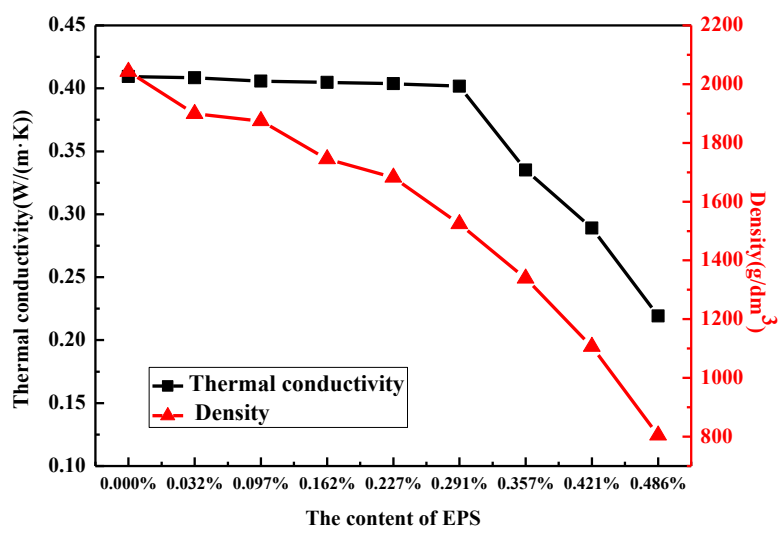

Fig. 3. The results of density and thermal conductivity with different EPS content

\subsection{The influence of fly ash on thermal conductivity and density}

In this part, thermal conductivity and density of the thermal insulation mortar with different fly ash contents were obtained at figure 4 .

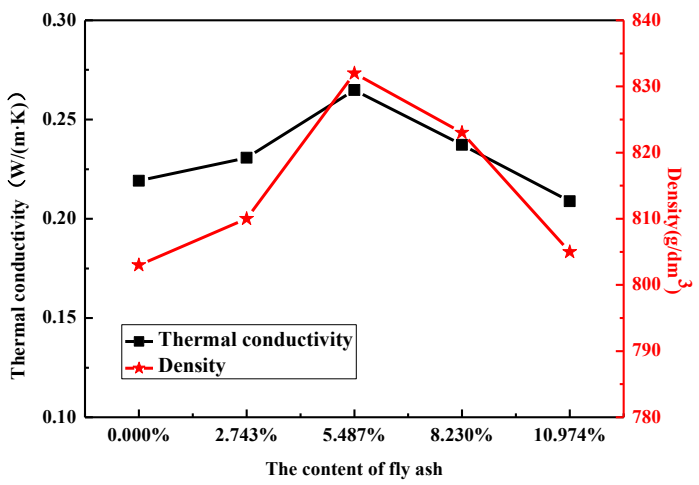

Fig. 4. Relationship between fly ash content and density and thermal conductivity
As the results show, with the increase of the fly ash content, the density and thermal conductivity of thermal insulation mortar both rised first and then fell. When the content of fly ash was $5.487 \%$, the density and thermal conductivity of thermal insulation mortar reached their maximum values, which were $832 \mathrm{~g} / \mathrm{dm}^{3}$ and 0.2649 $\mathrm{W} /(\mathrm{m} \cdot \mathrm{K})$ respectively. The reason could be that small amount (the content less than $5.487 \%$ ) of fly ash could be evenly distributed among the cement particles, which not only could fill the gaps between cement particles, but also improve the particle gradation of cementitious materials and increase the density of cement paste. However, due to the low density and spherical particles structure with more pores of fly ash [11], with the over using of fly ash, the proportion of cement paste decreased and the content of fly ash increased, which resulted in the decrease of thermal conductivity and density of thermal insulation mortar.

\section{Conclusions}

This paper prepared a composite thermal insulation mortar with magnesium oxychloride cement and EPS particles, and investgated the effect of EPS on the mechanical properties, density and thermal conductivity. Also, the influence of fly ash on thermal conductivity and density of thermal insulation mortar were studied. From the previous experimental results, the following conclusions could be made:

1) Generally, the compressive strength and flexural strength decrease along with EPS content in the thermal insulation mortar. When the content of EPS is $0.486 \%$, both the compressive strength and flexural strength reach minimum.

2) EPS particles can significantly reduce the density and thermal conductivity of thermal insulation mortar. When the EPS content is up to $0.0486 \%$, the density and thermal conductivity are $804.7-\mathrm{g} / \mathrm{dm}^{3}$ and 0.2191 $\mathrm{W} /(\mathrm{m} \cdot \mathrm{K})$ respectively.

3) When the fly ash content is $5.487 \%$, the density and thermal conductivity of the mortar reach the maximum, because of the filling effect of fly ash, Also, fly ash can significantly reduce the density and thermal conductivity because of its spherical particle structure of porous, when the content of fly ash is greater than $5.487 \%$.

\section{Acknowledgements}

The research reported was financially supported by Guangzhou Science and Technology Project (Grant No. 201902010072) and Science and Technology Project of Guangzhou Municipal Construction Group Co., Ltd. (Grant No. [2019]-KJ022, [2019]-KJ024). The financial supports are highly appreciated.

\section{References}

1. L. Xu, The vertical ignition process of External Thermal Insulation System based on Polystyrene 
Foam under a radiation heater. University of Science and Technology of China, 2014, Ph. D. Thesis.

2. Y.F. Guo, China Synthetic Resin and Plastics, Research progress into PS foamed plastics for building exterior wall heat insulation and flame retarding, 36 96-98 (2019)

3. H. Gao, C. Lin, G.Q. Geng, Modern Chemical Industry, Effect of magnesium oxychloride cement on flame retardance and physical properties of polystyrene cystosepiment, 36 111-113 (2016)

4. R. Tao, Experimental Study of Non-ignitable Emulsion Powder Expanded Polystyrene Particles Composite Insulation Mortar, Chongqing University, 2016, Master Thesis.

5. C.L. Wang, G.Q. Lan, C.Y. Jiang, Chongqing Architecture, Configuration of External Heat Preservation Mortar on Reclaimed Polyphenyl Granule Exterior Wall, 10 44-46 (2011)

6. Z. Liu, Q. Zhang, S.W. Xie, J.W. He, J.C. Jian, J.Y. Lin, Plastics Science and Technology, Surface Modification of Waste EPS Particles and Its Application in Geopolymer-based External Wall Thermal Insulation Materials, 43 56-61 (2015)

7. C.P. Wu, Study of External Wall Insulation System Based on Gelationous Powder and Expanded Polystyrene Pellets and Its Anti-cracking Properties, Chongqing University, 2013, Ph. D. Thesis.

8. A. Misra, R. Mathur, Bull Mater, Magnesium oxychloride cement concrete, 30 239-246 (2007)

9. W. Meng, F. Ju, J.M. Yin, Z.P. Ji, J. Wang, Jiangsu Building Materials, The effect of waste rubber powder on the mechanical properties of magnesium oxychloride cement, 03 23-26 (2018)

10. J.Y. Chu, Journal of Shenyang Jianzhu University (Natural Science), Impact of Rubber on Polystyrene Granule Physical Properties, 32 141-147 (2016)

11. W. Xue, B.B. Zhang, Concrete, Thermal insulation material of magnesium oxychloride cement dosage of fly ash modification research, -11 67-70 (2018) 